\title{
Common Microflora Encountered in Reproductive Tract of Indigenous Pigs in Tamil Nadu, India
}

\author{
K. Sangli Vikram Kumar ${ }^{1 *}$, N.R. Senthil ${ }^{2}$ and D. Balasubramanyam ${ }^{3}$ \\ ${ }^{1}$ Department of Animal Genetics and Breeding, Madras Veterinary College, \\ Chennai - 600 007, Tamil Nadu, India \\ ${ }^{2}$ Centralized Clinical Laboratory, Madras Veterinary College, Chennai - 600007 , \\ Tamil Nadu, India \\ ${ }^{3}$ Pig Breeding Unit, Post Graduate Research Institute in Animal Sciences, \\ Kattupakkam - 603 203, Tamil Nadu, India \\ *Corresponding author
}

A B S T R A C T

\begin{tabular}{|l|l|l|l|l|l}
\hline Keywords & $\begin{array}{l}\text { Reproductive diseases are one of the most important problems in the pigs } \\
\text { reared under scavenging system and are considered as one of the most } \\
\text { Microflora, } \\
\text { Reproductive tract, } \\
\text { Indigenous pigs, } \\
\text { Tamil Nadu. }\end{array}$ & $\begin{array}{l}\text { Swab samples were collected from indigenous pigs from different districts } \\
\text { of Tamil Nadu. Collected samples were inoculated, incubated and cultured } \\
\text { for the common microflora found in the reproductive tract of indigenous } \\
\text { pigs. Twenty four samples were positive for Streptococcus sp., twenty }\end{array}$ \\
\cline { 1 - 2 } Article Info & $\begin{array}{l}\text { samples were positive for E. coli sp., eleven samples were positive for } \\
\text { Accepted: } \\
\begin{array}{l}\text { 29 September 2017 } \\
\text { Available Online: } \\
10 \text { October 2017 }\end{array}\end{array}$ & $\begin{array}{l}\text { Staphylococcus sp., and two samples for Pseudomonas sp. and one sample } \\
\text { showed colonies similar to Brucella sp. }\end{array}$ \\
\hline \hline
\end{tabular}

\section{Introduction}

The bicornuate porcine uterus with a urogenital sinus, cervical pulvini and proportion of layers with cyclic alterations in pigs facilitate microbial invasion. Reproductive diseases are one of the most important problems in the pigs reared under scavenging system and are considered as one of the most threatening problem in indigenous pig production. Huge economic loss is encountered due to abortion, still birth and reduced fertility rate in case of infectious pathogens like Brucella suis, Leptospira sp. and some viral agents like Porcine parvo and circo viruses. The secondary agents that are important include infection caused by Pasteurella multocida, Streptococcus suis, Actinobacillus suis (De Clercq et al., 2013; O'Meara et al., 2014). Abnormal vaginal microbiota is concerned with high risk of obstetrical and gynaecologic complications. Vulval discharges are the best indicator of any infections in reproductive or urogenital tract. For a successive reproductive rate, the system should be free from infections. Screening of 
animals for its microbial load will aid in detection of infection, managemental errors and also can improve the performance of the breeding herd. No such study was carried out in indigenous pigs of Tamil Nadu. Hence the study was taken up to evaluate the common microflora occurrence in reproductive tract of indigenous pigs.

\section{Materials and Methods}

A total of 58 vaginal swab samples were collected from indigenous pigs from different districts of Tamil Nadu. Collected samples were inoculated into nutrient broth (HimediaMM244) and incubated at $37^{\circ} \mathrm{C}$ for overnight. The turbid samples were further inoculated in solid media such as Mannitol salt agar (Himedia- M118), EMB agar (Hi-media M317) and MacConkey agar (HimediaM081B). Biochemical tests were conducted to confirm the genus and specific organisms. Gram staining and Modified Ziehl Neelson staining were also done (Figs. 1-9).

\section{Results and Discussion}

Out of fifty eight vaginal swab samples, twenty four samples were positive for streptococcus sp., twenty samples were positive for $E$. coli sp., eleven samples were positive for staphylococcus sp., and two samples for Pseudomonas sp. and one sample showed colonies similar to Brucella sp. Of

Fig.1 Staphylococcus sp. (Gram's staining)

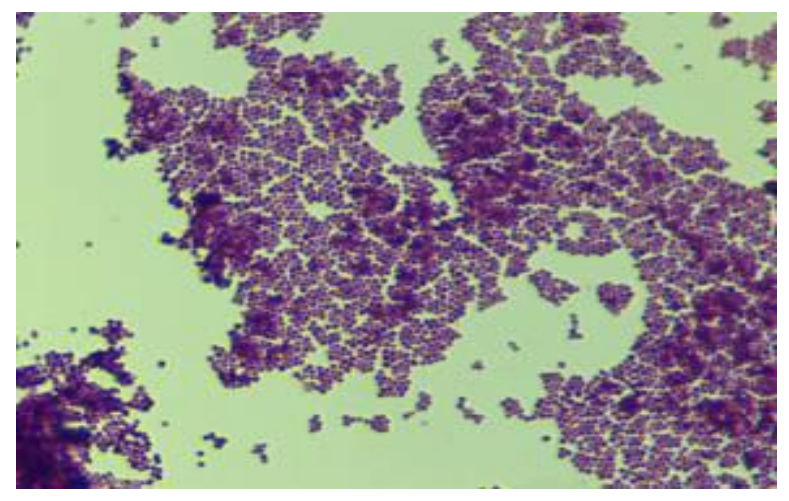

these, fifty eight samples cultured, more than one bacterial organism was isolated from seven samples. Our finding are similar to Bara et al., (1993) who reported commonly encountered species are Streptococcus sp., Staphylococcus sp., Enterobacteria, Corynebacterium sp., Micrococcus sp. and Actinobacillus $s p$. In healthy pigs, the vaginal flora has been characterized by culture dependent methods and was found to include both aerobic and anaerobic bacteria with the most prominent being the following organisms were Streptococcus sp., E. coli, Staphylococcus sp., Corynebacterium sp., Micrococcus sp. and Actinobacillus sp.

This type of microbial environment in indigenous pigs were due to unhygienic practices and at the time of mating included venereal transmission, damage to the cervix during mating and faecal contamination and also the same was concurred by Brummelman (1980) and Waggman et al., (1988). Larsen and Gatask (1980) also opined that microbial colonization were also due to change in the hormonal environment such as estrogen.

Streptococcus and E. coli were the predominant pathogens of the microbial population in which Streptococcus is an environment pathogen whereas $E$. coli infection may be due to faecal contamination of the animals without showing any characteristic clinical cases.

Fig.2 Psedomonas sp. (Gram's staining)

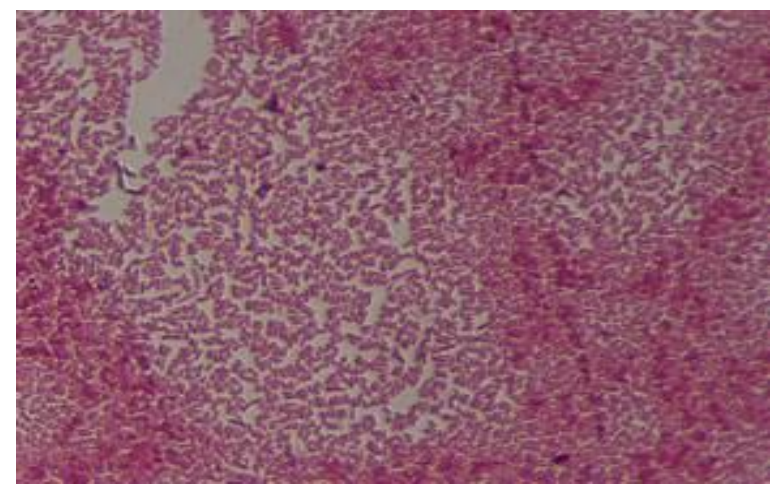


Fig.3 Streptococcus sp. (Gram's staining)

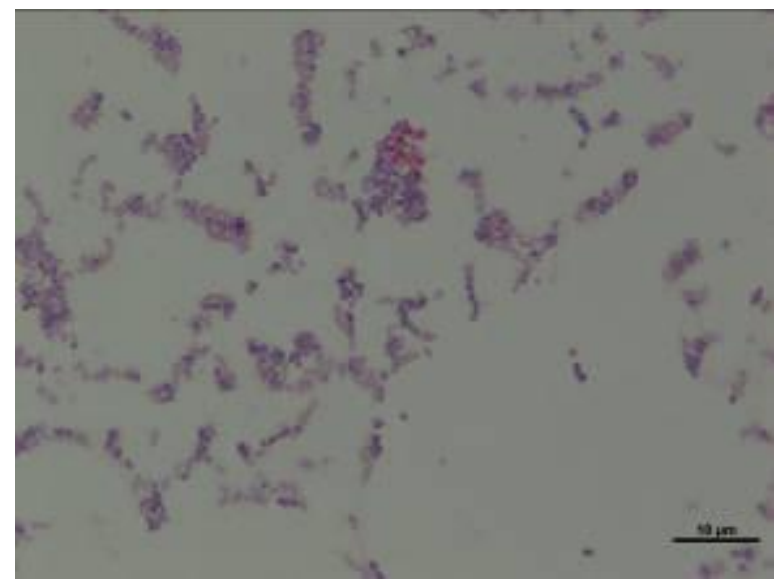

Fig.5 Pseudomonas sp. (culture)

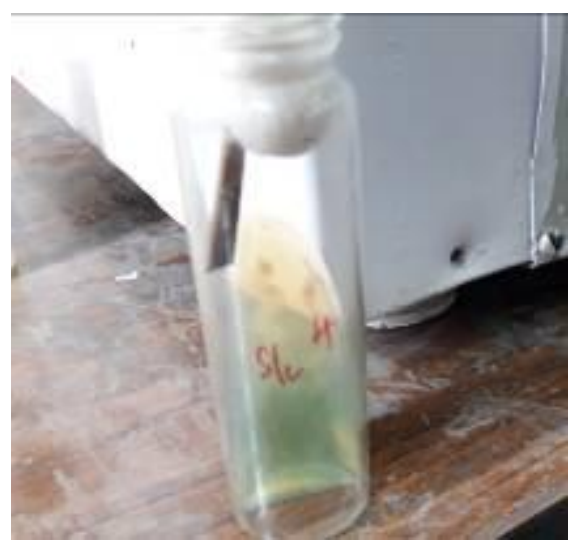

Fig.7 Test for oxidase

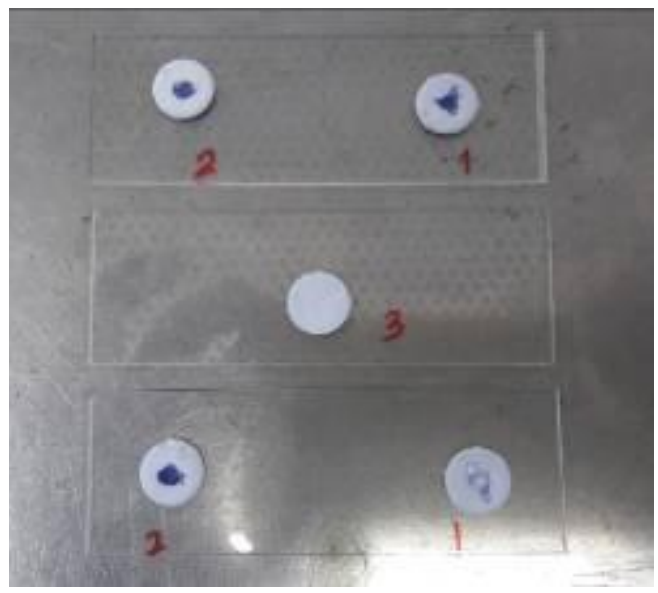

Fig.4 E. coli (EMB agar)

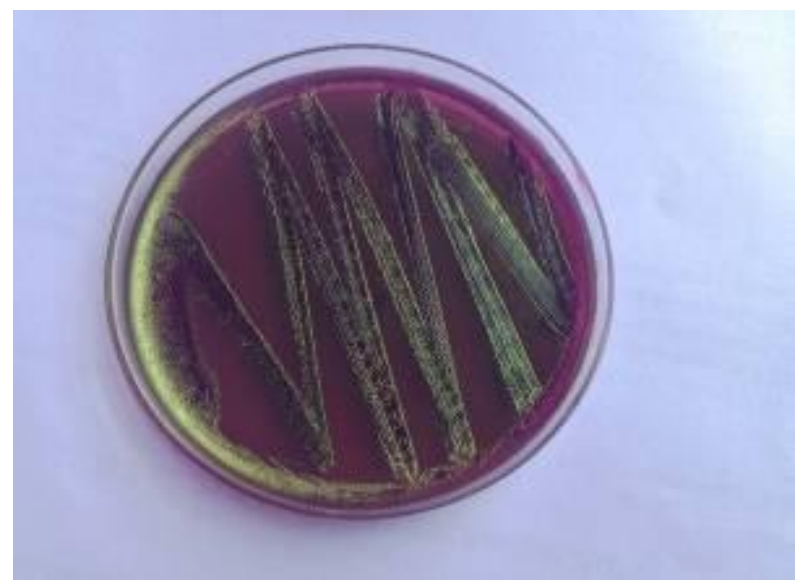

Fig.6 Lead acetate test (Brucella sp.)

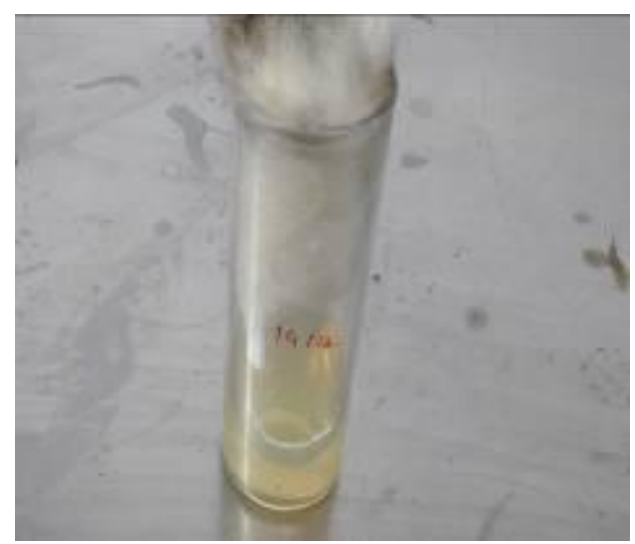

Fig.8 Plate showing growth of Brucella sp.

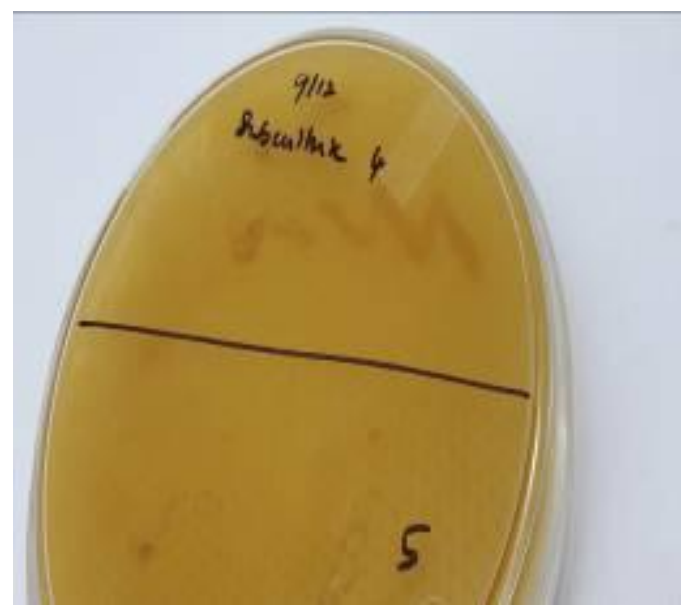


Fig.9 Test for catalase (Brucella sp.)

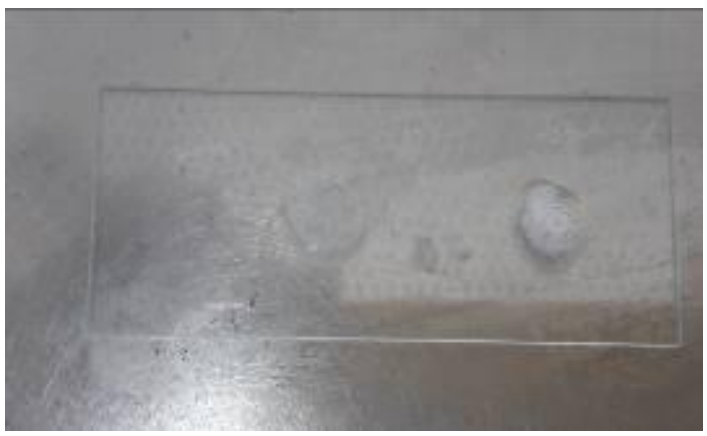

Vaginal micro flora is the effective defense criteria for reproductive function and for maintaining the healthy environment. It prevents the proliferation of microbes that are strange to the vagina (Linhares et al., 2010). Depending on the exogenous and endogenous factors, the composition of the vaginal flora may change. If there is some alteration in the vaginal environment, the level of flora tends to vary. Estrus stage of cervix will also influence the flora in normal reproductive tract.

In conclusion, urogenital infections are one of the pesky problems that the indigenous pig farmers must deal with. Identifying the etiology regarding the infections pertaining to reproductive tract of scavenging indigenous pigs was difficult. Prevention rather than treatment is the only key to overcome such difficulties. Moreover, hygienic and controlled system of rearing of indigenous pigs is warranted.

There is a temporary microbial load in the cervico-vaginal region (anterior), consisting of ample amount of bacteria (gram positive and gram negative, aerobic and anaerobic bacteria) with different potentially pathogenic properties. Many of these bacteria are competent and also have the capacity to act as a root of infections for many diseases as far as reproductive tract is concerned. So, further investigations are necessary in order to comprehend the infections of the reproductive tract of indigenous pigs.

\section{Acknowledgement}

Above all, I would like to thank all the indigenous pig farmers, Veterinary Assistant Surgeons who helped and supported me during this study.

\section{References}

Bara, M., McGowan M, O'Boyle D and Cameron R. A study of the microbial flora of the anterior vagina of normal sows during different stages of the reproductive cycle. Aust. Vet. J., 1993; 70:256-259. doi: 10.1111/j.17510813.1993.tb08043.x.

Brummelman, B., 1980. Proc Inf Pig Vet Soc, Copenhagen, p 56

De Clercq, E., Kalmar, I and Vanrompay D. Animal models for studying female genital tract infection with Chlamydia trachomatis. Infect. Immun., 2013. 81: 3060-3067. doi: 10.1128/IAI.00357-13.

Lanen, B., and Gatask RP 1980. Ohref Gynaecol 55: 100.

Linhares, I.M., Paulo Cesar Giraldo and Edmund Chada Baracat. 2010. New Findings about Vaginal Bacterial Flora. Rev. Assoc. Med. Bras., 2010. 56(3): 370-4

O'Meara, C.P., Andrew DW and Beagley 
KW. The mouse model of Chlamydia genital tract infection: A review of infection, disease, immunity and vaccine development. Curr. Mol. Med., 2014; 14:396-421. doi:
10.2174/15665240113136660078. Wegmann, P., Bertschinger HU and Eng V 1988. Proc Inf Pig Vet Soc, Rio de Janeiro: $\mathrm{p} 302$.

\section{How to cite this article:}

Sangli Vikram Kumar, K., N.R. Senthil and Balasubramanyam, D. 2017. Common Microflora Encountered in Reproductive Tract of Indigenous Pigs in Tamil Nadu. Int.J.Curr.Microbiol.App.Sci. 6(10): 4709-4713. doi: https://doi.org/10.20546/ijcmas.2017.610.436 $\mathrm{xx}$ 